\title{
EXTRADIGITAL GLOMUS TUMOUR CAUSING THIGH PAIN
}

\author{
A CASE REPORT \\ S. AMILLO, F. J. ARRIOLA, G. MUÑOZ \\ From the University of Navarra, Pamplona, Spain
}

\begin{abstract}
Glomus tumours are rare and benign, arising from a neuromyoarterial glomus body, most commonly in the hand. We report a patient with such a tumour in an atypical site, the right vastus lateralis. Pain was aggravated by muscle contraction, and ultrasonography and MRI were required to locate the lesion accurately. Surgical excision gave immediate pain relief.
\end{abstract}

J Bone Joint Surg [Br] 1997;79-B:104-6.

Received 28 May 1996; Accepted after revision 25 September 1996

Glomus tumours are rare, benign hamartomas arising from neuromyoarterial glomus bodies. Most occur in a distal phalanx, often beneath the nail, but they may develop anywhere. ${ }^{1}$ The classical triad of aching pain, exquisite tenderness and temperature sensitivity often provides the diagnosis, but an atypical anatomical site and the usually small size of the tumour may make this difficult. We report a patient with a glomus tumour in the right vastus lateralis. This caused pain which was made worse by contraction of the muscle, and so produced considerable wasting of the thigh.

\section{CASE REPORT}

A 38-year-old woman was referred with an 18-year history of thigh pain. Three previous excisional biopsies, taken eight, seven and six years earlier had shown no histopathological findings. She had been treated in a chronic pain unit

S. Amillo, MD, Assistant Professor of Orthopaedic Surgery

University Clinic, School of Medicine, University of Navarra, Pio XII no 36, E-31008 Pamplona, Spain.

F. J. Arriola, MD, Resident

Sancho el Fuerte no 77, 15-G 31008 Pamplona, Spain.

G. Muñoz, MD, Resident

Cultura no 5, 5-D Barañain, Spain.

Correspondence should be sent to Dr S. Amillo.

(C)1997 British Editorial Society of Bone and Joint Surgery 0301-620X/97/16951\$2.00 for 'idiopathic myalgia', with no improvement.

She had an antalgic gait, with marked wasting of the right thigh and especially the vastus lateralis. She could not extend her right knee actively because of the pain on contraction of the muscle. There was an acute point of tenderness in its distal third, but no swelling, redness or local hyperaemia and no palpable mass. The passive range of movement at hip and knee was normal.

Radiographs were normal, but ultrasonography of the painful area revealed a well-defined hypoechoic oval mass (Fig. 1). MRI on a 1 Tesla unit (Magneton, Siemens, Medical Systems, Erlangen, Germany) showed a well-

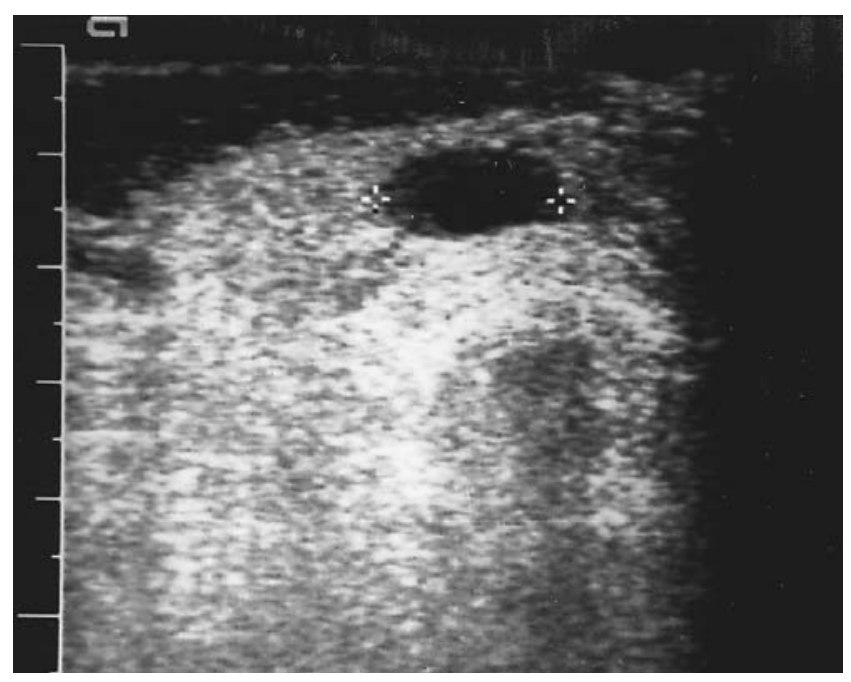

Fig. 1

Longitudinal Doppler scan of the lateral aspect of the thigh showing a well-localised hypoechoic mass.

delineated nodule $3 \mathrm{~cm}$ in length with a longitudinal axis in the distal third of the vastus lateralis. The T1-weighted image showed a hypointense ovoid tumour (Fig. 2a), which was enhanced by injection of gadolinium (Fig. 2b). The T2weighted images were hyperintense (Fig. 3).

The mass was excised (Fig. 4) and the histopathological findings confirmed the diagnosis of a glomus tumour (Fig. 5 ). The patient had immediate relief of pain and at followup examination 12 months later was asymptomatic. 


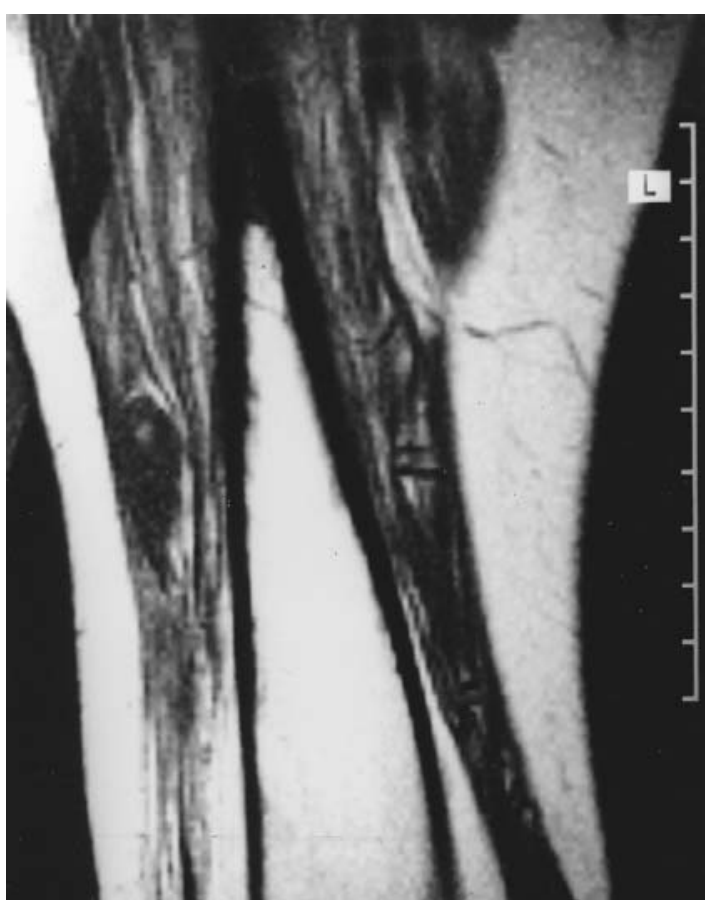

Fig. 2a

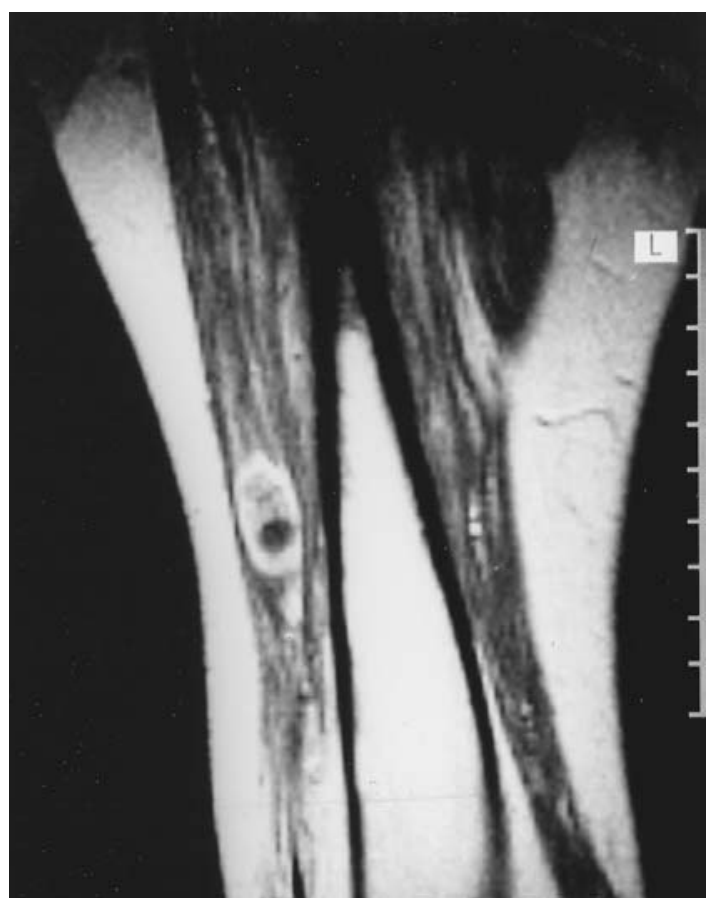

Fig. 2b

MRI of the thigh showing a hypointense oval lesion (a), enhancing with injection of gadolinium (b) on the T1-weighted image.

\section{DISCUSSION}

A typical glomus tumour of the hand is readily diagnosed ${ }^{2}$, but it may occur in the trunk, the extremities or the submucosal tissues and present a diagnostic dilemma. Its small size and possible deeper location $^{7-9}$ such as in

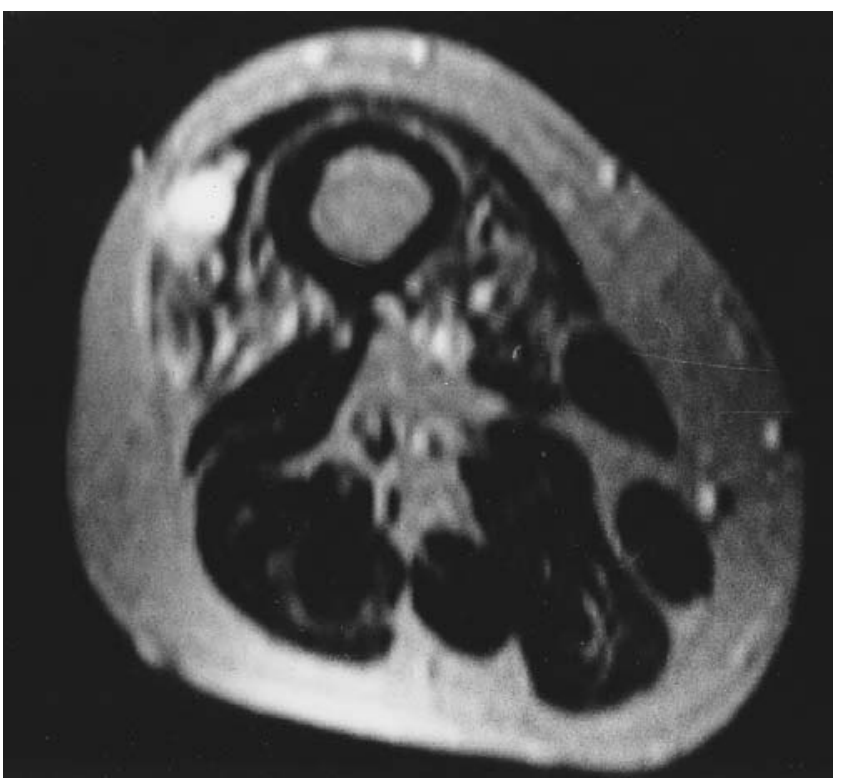

Fig. 3

Axial MRI of the glomus tumour, which is hyperintense on the T2weighted image. There is marked wasting of the thigh. striated muscle ${ }^{10}$ makes localisation difficult and may delay treatment. In our case, marked wasting of the thigh, an antalgic gait, pain on contraction of vastus lateralis, hyperaesthesia, and acute point tenderness allowed a clinical diagnosis to be made. There are no specific imaging techniques to confirm the diagnosis, but ultrasonography, despite its low specificity, helped to locate the lesion. ${ }^{8}$ MRI gave more detail of the lesion and its relationship to

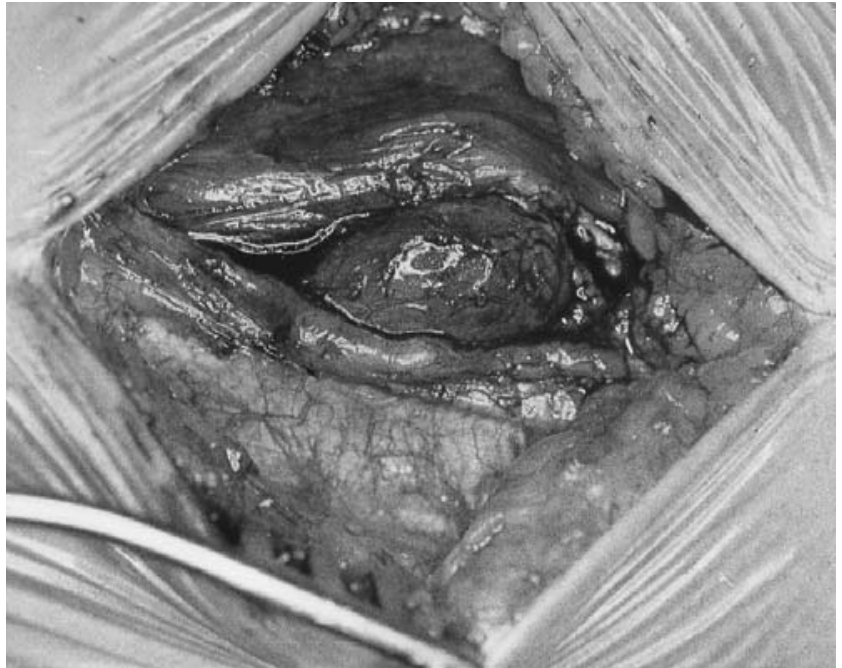

Fig. 4

Intraoperative photograph showing the $3 \mathrm{~cm}$ brown, oval, well-encapsulated mass arising from vastus lateralis. 


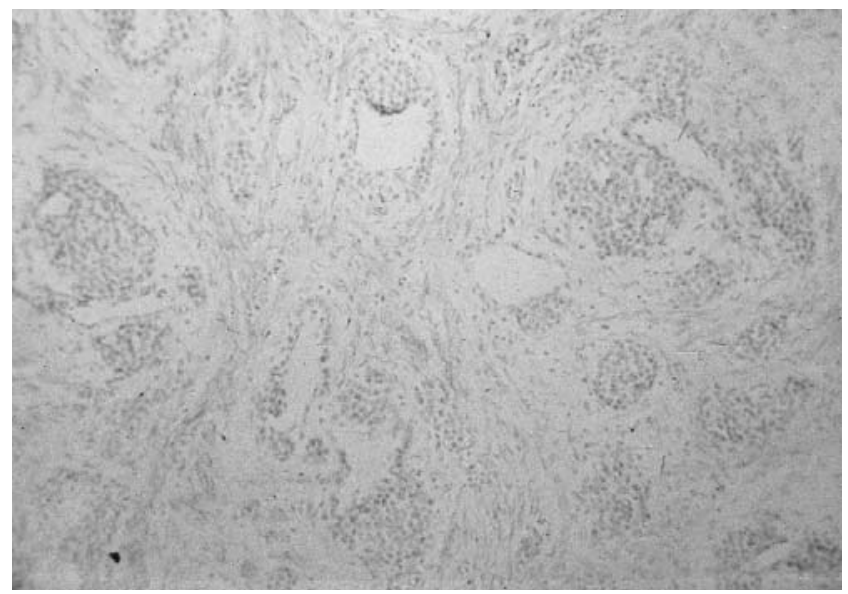

Fig. 5

Photomicrograph of the tumour showing lobules, epithelioid cells proliferating in sheet-like fashion, with irregular thin-walled vessels (haematoxylin and eosin $\times 60$ ).

the adjacent structures, and allowed complete removal by excision. $^{12-14}$

A glomus tumour should be considered in the differential diagnosis of any painful, benign mass in a limb. ${ }^{5}$ An early and accurate diagnosis will prevent unnecessary procedures, ${ }^{4,7,15-17}$ and final proof can be provided by the histopathological findings. ${ }^{18}$

No benefits in any form have been received or will be received from a commercial party related directly or indirectly to the subject of this article.

\section{REFERENCES}

1. Ayala H, Villas C, Cañadell J. Glomus tumor. Acta Orthop Belg 1980;46:219-25.

2. Carroll RD, Berman AT. Glomus tumors of the hand: review of the literature and report on twenty-eight cases. J Bone Joint Surg [Am] 1972;54-A:691-703.

3. Caughey DE, Highton TC. Glomus tumour of the knee: report of a case. J Bone Joint Surg [Br] 1966;48-B:134-7.

4. Smyth M. Glomus-cell tumors in the lower extremity: report of two cases. J Bone Joint Surg [Am] 1971;53-A:157-9.

5. Garrell RH, Oates E. Glomus tumor of the thigh (Letter). $A M J$ Roentgenol 1990;155:423.

6. Mabit C, Pécout C, Arnaud JP. Glomus tumor in the patellar ligament: a case report. J Bone Joint Surg [Am] 1995;77-A:140-1.

7. Quigley JT. A glomus tumor of the heel pad: a case report. $J$ Bone Joint Surg [Am] 1979;61-A:443-4.

8. Fornage BD. Glomus tumors in the fingers: diagnosis with ultrasound. Radiology 1988;167:183-5.

9. Heje M, Bang C, Jensen SS. Glomus tumours causing limb hypoplasia? J Bone Joint Surg [Br] 1992;74-B:779-80.

10. Mathis WH, Schulz MD. Roentgen diagnosis of glomus tumors. Radiology 1948;51:71-5.

11. Smith KA, Mackinnon SE, Macauley RJB, Mailis A. Glomus tumor originating in the radial nerve: a case report. J Hand Surg Am 1992;17:665-7.

12. Goettmann S, Drape JL, Idy-Peretti I, et al. Magnetic resonance imaging: a new tool in the diagnosis of tumours of the nail apparatus. Br J Dermatol 1994;130:701-10.

13. Jablon M, Horowitz A, Bernstein DA. Magnetic resonance imaging of a glomus tumor of the fingertip. J Hand Surg Am 1990;15:507-9.

14. Matloub HS, Muoneke VN, Prevel CD, Sanger JR, Yousif NJ. Glomus tumor imaging: use of MRI for localization of occult lesions. J Hand Surg Am 1992;17:472-5.

15. Rettig AC, Strickland JW. Glomus tumor of the digits. J Hand Surg 1977;2:261-5.

16. Chan CW. Intraosseous glomus tumor: case report. J Hand Surg Am 1981;6:368-9.

17. Corrado EM, Passaretti U, Messore L, Lanza F. Thermographic diagnosis of glomus tumor. Hand 1982;14:21-4.

18. Tsuneyoshi M, Enjoji M. Glomus tumor: a clinico-pathologic and electron microscopic study. Cancer 1982;50:1601-7. 